\title{
Optimization of Inspection Process for Quality Assurance
}

\author{
Parth Khandekar', Aspi Dadina² \\ ${ }^{1}$ Mumbai University, Fr. Conceicao Rodrigues College of Engineering, \\ Bandstand, Bandra West, Mumbai 400051, India \\ ${ }^{2}$ Godrej \& Boyce Mfg. Co. Ltd, Locking Solutions \& Systems, \\ Pirojsha Nagar, Vikhroli East, Mumbai 400079, India
}

\begin{abstract}
This is project based on the optimization of the inspection process of the driving cams used in the petroleum $3 k$-s padlock. Even though this paper is related to the inspection of one type of component, the optimization analysis can be used to plan the inspection process for similar components.
\end{abstract}

Keywords: 3KS - Technology, Padlock, Driving Cam, Locking Bolt, Locking Mechanism, Gauge

\section{Introduction}

In Godrej and Boyce Mfg. Co. Ltd there are various locks manufactured based on different security levels. These levels are defined by the company according to their mechanism used for locking solution. There are 5 security levels. In this research we will have a look at the inspection process for padlock with 3ks technology with security level- 4 known as petroleum lock or 3KS- Padlock.

This is the lock in which the locking mechanism works without any lever. This has new technology of the 3k-s where the locking is done using the driving cam, locking bolt and the ball bearing.

For each of the components there is a specific inspection plan as well as specific checklist. In this research paper we will stick to the inspection of the driving cam. Driving cam is the component used for locking and unlocking of the shackle. The other parts in the locking mechanism are locking bolt, connecting link \& ball bearing.

There are various locks in the industry of locking solutions with different types of mechanisms. In Godrej \& Boyce, all the various types of locks with different unique mechanisms are produced. Some of them are based on lever mechanism, some on electronics or some on driving cam n locking bolt mechanism.

In this paper we will have a look at the lock with 3KS technology.

The Figure 1 shows the petroleum lock while Figure 2 shows the driving cam which is one of the most important parts of the locking mechanism.

There are various components of the lock namely body, shackle, locking bolt, driving cam, connecting link, ball bearing, screws, cylinder body with pins, weather cap, sliding, free spin hard disc, springs and keys.

The mechanism is such that when the key is rotated it rotates the driving cam such that the movement of the locking bolt takes place. This movement then allows the locking and unlocking of the shackle. One of the important features of this lock is that the key will only come out when the lock is in locked position and not while it is unlocked. Also the key code is very unique and it is almost impossible to duplicate the key outside the factory. Due to all these reasons the lock has got higher price than other locks.

Figure 3 shows the drawing for the driving cam and its dimensions which are important from functionality point of view. For this driving cam to work functionally there are various measuring parameters which one needs to check. Some parameters are checked by vernier while others are checked with the help of gauges made for the inspection.

In this paper we will take the overview for the method of inspection and optimization of the method which can help in saving cost, time and human efforts for the inspection of the driving cam.

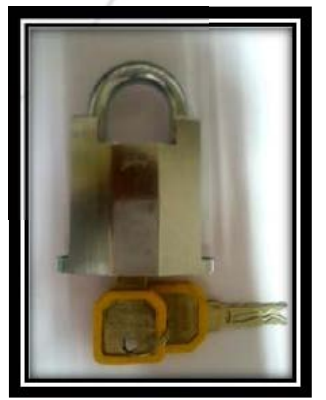

Figure 1: 3K-S pad lock

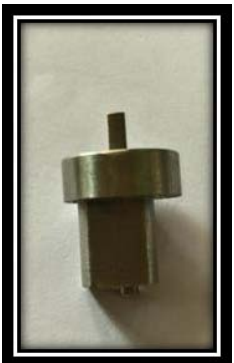

Figure 2: Driving Cam 


\section{International Journal of Science and Research (IJSR) \\ ISSN (Online): 2319-7064}

Index Copernicus Value (2013): 6.14 | Impact Factor (2015): 6.391

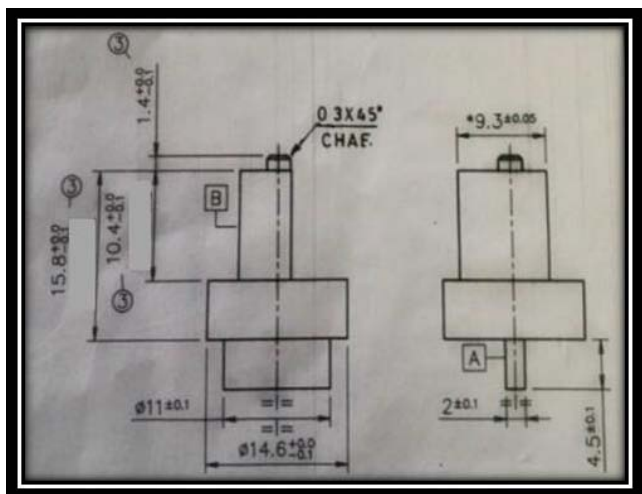

Figure 3: Drawing For Driving Cam

\section{Current Method}

Currently there are 10 gauges as shown in figure 4 for the inspection of driving cams and a vernier calliper for measuring few parameters like thickness of rib. Every gauge is used to check different parameters separately. Table 1 shows the gauge number, purpose of gauge and its cost incurred.

Table 1: Details of gauges required for old process

\begin{tabular}{|c|c|c|}
\hline Gauge Number & Purpose & Cost \\
\hline PDL $-119-46-\mathrm{G} 1$ & Width of lug & 690 \\
\hline PDL $-119-46-\mathrm{G} 2$ & Lug profile & 7300 \\
\hline PDL $-119-46-\mathrm{G} 3$ & Outer diameter & 715 \\
\hline PDL $-119-46-\mathrm{G} 4$ & Height & 690 \\
\hline PDL $-119-46-\mathrm{G} 5$ & Lug height & 2250 \\
\hline PDL $-119-46-\mathrm{G} 6$ & Length of rib & 690 \\
\hline PDL $-119-46-\mathrm{G} 7$ & Bottom profile & 2350 \\
\hline PDL $-119-46-\mathrm{G} 8$ & Profile & 3500 \\
\hline PDL $-119-46-\mathrm{G} 9$ & Overall height & 690 \\
\hline PDL $-119-46-$ G10 & Profile gauge & 6950 \\
\hline Total Cost & & 25825 \\
\hline
\end{tabular}

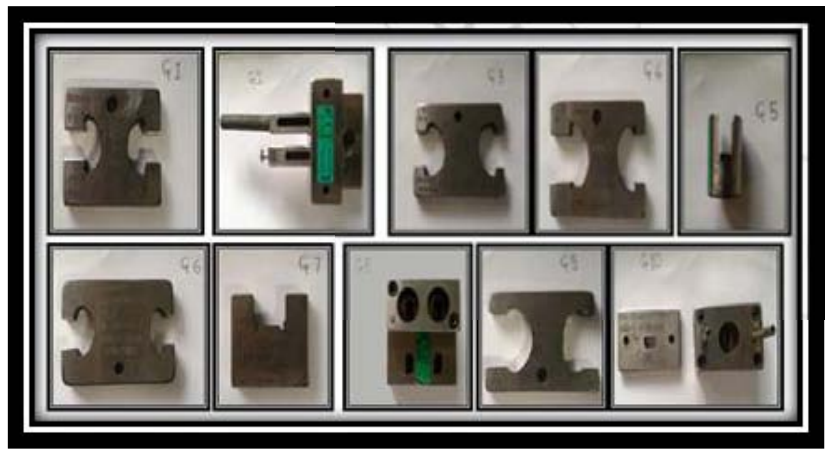

Figure 4: All gauges used in current method

These gauges are designed for inspection of the driving cams only and they cannot be used for any other component. Therefore the cost incurred is 25825 Rs is only for driving cam inspection. Also it is the cost of one set of gauges. If the sets of gauges are increased then the total cost will increase accordingly.

\section{New Method}

In this the process needs to be modified a little bit. If all gauges are used then the driving cams can be inspected in any random sequence but in order to reduce the number of gauges we need to follow certain inspection path. One driving cam is checked for different parameters in these 10 gauges for its acceptance. But after following these steps it is possible to inspect the driving cam using only 3 gauges and a digital vernier calliper for the driving cam to be accepted for functional working.

- Measure the dimensions [15.8 (- 0.1) mm], [5.4 (+/- 0.1) $\mathrm{mm}]$, Rib thickness $[2(+/-0.1) \mathrm{mm}]$, diameter from which the rib is made is [11 (+/- 0.1)] \& diameter [14.6 (- 0.1)] using the vernier calliper. If the cam qualifies for these measurements then go to next step else reject.

- Use the gauge G8 Shown in Figure 4 for qualifying all the parameters of the lug profile. It also checks the critical dimension of [9.3(+/- 0.05)].

- Concentricity of the diameter, lug profile and rib can be checked using G10 gauge shown in Figure 4.

- In the gauge G2 from bottom side slot the rib length can be inspected. The thickness and length acceptance or rejection is done using this slot. Since all the parameters are measured properly the positioning of the lug can be observed using gauge number G2 shown in Figure 4.
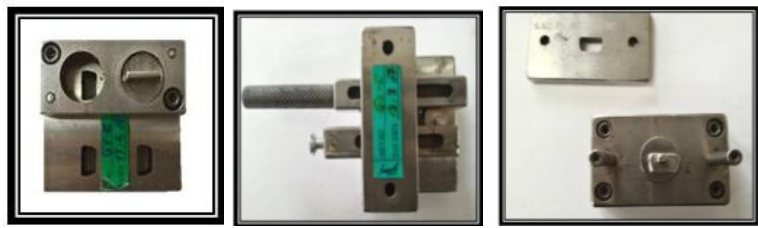

Figure 5: Shortlisted Gauges

Table 2: Details of gauges required for new process

\begin{tabular}{|c|c|c|}
\hline Gauge Number & Purpose & Cost \\
\hline PDL $-119-46-$ G2 & Lug profile & 7300 \\
\hline PDL $-119-46-$ G8 & Profile & 3500 \\
\hline PDL $-119-46-$ G10 & Profile gauge & 6950 \\
\hline Total Cost & & 17750 \\
\hline
\end{tabular}

From above table it can be seen that the total cost now has gone down to 17750 Rs. Also there exists the need of a vernier calliper for inspecting few dimensions. Even though there exists some cost of vernier calliper virtually the cost of it is zero since it can be used for measuring any other component and it is not like the gauges in the old method where they can be used for one single dimension only. So the cost of vernier calliper is neglected.

\section{Benefits}

- Time required to measure the driving cams is reduced.

- Operator fatigue is reduced.

- This study can be implemented to other such components.

\section{Cost Benefits}

This is one of the criteria in the benefits.

The calculation below shows the cost which can be saved if the above method is followed.

If all the gauges are used then: -

Total cost of gauges $=25825$ Rs. 


\section{International Journal of Science and Research (IJSR) \\ ISSN (Online): 2319-7064}

Index Copernicus Value (2013): 6.14 | Impact Factor (2015): 6.391

If the new method is implemented then: -

Gauges which can be eliminated are = G1, G3, G4, G5, G6, G7, G9.

Total Cost of these gauges $=8075$ Rs.

And total cost incurred using new process and gauges as shown in Table $2=17750$ Rs.

Therefore 8075 Rs is the cost saved if the new process is used.

\section{References}

[1] All the drawings and pictures for gauges and lock are taken from the quality assurance department of Godrej \& Boyce Locking Solutions and Systems. All Rights Reserved By Godrej \& Boyce Mfg. Co. Ltd. Locks Division, Pirojsha Nagar, Vikhroli, Mumbai - 400079.

\section{Author Profile}

Parth Khandekar is currently pursuing B.E. degree in Production Engineering from Fr. Conceicao Rodrigues College of Engineering. While completing the degree, is currently working in Godrej \& Boyce Mfg. Co. Ltd., Locks division, Quality Assurance Department for In-plant training.

Aspi Dadhina received MSc degree in engineering business management from Warwick University, United Kingdom. He is working as the General manager \& head of quality assurance department in the locks division of Godrej \& Boyce Mfg. Co. Ltd. 